\title{
Calibrating abundance indices with population size estimators of red back salamanders (Plethodon cinereus) in a New England forest
}

Ahmed A Siddig, Aaron M Ellison, Scott Jackson

Herpetologists and conservation biologists frequently use convenient and cost-effective, but less accurate, abundance indices (e.g., number of individuals collected under artificial cover boards or during natural objects surveys) in lieu of more accurate, but costly and destructive, population size estimators to detect and monitor size, state, and trends of amphibian populations. Although there are advantages and disadvantages to each approach, reliable use of abundance indices requires that they be calibrated with accurate population estimators. Such calibrations, however, are rare. The red back salamander, Plethodon cinereus, is an ecologically useful indicator species of forest dynamics, and accurate calibration of indices of salamander abundance could increase the reliability of abundance indices used in monitoring programs. We calibrated abundance indices derived from surveys of $P$. cinereus under artificial cover boards or natural objects with a more accurate estimator of their population size in a New England forest. Average densities $/ \mathrm{m}^{2}$ and capture probabilities of $P$. cinereus under natural objects or cover boards in independent, replicate sites at the Harvard Forest (Petersham, Massachusetts, USA) were similar in stands dominated by Tsuga canadensis (eastern hemlock) and deciduous hardwood species (predominantly Quercus rubra [red oak] and Acer rubrum [red maple]). The abundance index based on salamanders surveyed under natural objects was significantly associated with density estimates of $P$. cinereus derived from depletion (removal) surveys, but underestimated true density by $50 \%$. In contrast, the abundance index based on cover-board surveys overestimated true density by a factor of 8 and the association between the cover-board index and the density estimates was not statistically significant. We conclude that when calibrated and used appropriately, some abundance indices may provide cost-effective and reliable measures of $P$. cinereus abundance that could be used in conservation assessments and long-term monitoring at Harvard Forest and other northeastern USA forests. 
2 Calibrating abundance indices with population size estimators of red back salamanders

3 (Plethodon cinereus) in a New England forest

4 Ahmed A. Siddig ${ }^{1,2}$, Aaron M. Ellison², and Scott Jackson ${ }^{1}$

$5 \quad{ }^{1}$ University of Massachusetts Amherst, Dept. of Environmental Conservation

6160 Holdsworth Way, Amherst, Massachusetts 01003 USA

$7 \quad{ }^{2}$ Harvard University, Harvard Forest

8324 N. Main Street, Petersham, Massachusetts 01366 USA

9

10

11

12

13

14 asiddig@eco.umass.edu

15 ahmedsiddig@,fas.harvard.edu

16 Phone (office): 9787566186

17 Phone (cell): 4136951059

18

19 Abstract 
20 Herpetologists and conservation biologists frequently use convenient and cost-effective, but less

21 accurate, abundance indices (e.g., number of individuals collected under artificial cover boards or

22 during natural objects surveys) in lieu of more accurate, but costly and destructive, population size

23 estimators to detect and monitor size, state, and trends of amphibian populations. Although there are

24 advantages and disadvantages to each approach, reliable use of abundance indices requires that they be

25 calibrated with accurate population estimators. Such calibrations, however, are rare. The red back

26 salamander, Plethodon cinereus, is an ecologically useful indicator species of forest dynamics, and

27 accurate calibration of indices of salamander abundance could increase the reliability of abundance

28 indices used in monitoring programs. We calibrated abundance indices derived from surveys of $P$.

29 cinereus under artificial cover boards or natural objects with a more accurate estimator of their

30 population size in a New England forest. Average densities $/ \mathrm{m}^{2}$ and capture probabilities of $P$. cinereus

31 under natural objects or cover boards in independent, replicate sites at the Harvard Forest (Petersham,

32 Massachusetts, USA) were similar in stands dominated by Tsuga canadensis (eastern hemlock) and

33 deciduous hardwood species (predominantly Quercus rubra [red oak] and Acer rubrum [red maple]).

34 The abundance index based on salamanders surveyed under natural objects was significantly associated

35 with density estimates of $P$. cinereus derived from depletion (removal) surveys, but underestimated

36 true density by $50 \%$. In contrast, the abundance index based on cover-board surveys overestimated true

37 density by a factor of 8 and the association between the cover-board index and the density estimates

38 was not statistically significant. We conclude that when calibrated and used appropriately, some

39 abundance indices may provide cost-effective and reliable measures of $P$. cinereus abundance that

40 could be used in conservation assessments and long-term monitoring at Harvard Forest and other

41 northeastern USA forests. 
42 Keywords: Abundance index, amphibian monitoring, artificial cover boards, depletion sampling, 43 indicator species, long-term monitoring, Plethodon cinereus, population size, regression calibration, 44 removal sampling, salamander, Tsuga canadensis.

\section{Introduction}

Amphibians are declining worldwide due to climatic changes, habitat loss and alteration, invasive species, diseases, and environmental pollution (Becker et al., 2007; Dodd, 2010); the number of threatened amphibian species increased nine-fold between 1996 and 2011 (Lanoo, 2005; ICUN, 2011). Because amphibians are physiologically sensitive to many local environmental characteristics, they are thought to be useful indicator species for monitoring local environmental changes (Welsh \& Hodgson, 2013, but see Kerby et al., 2010). Thus, the overall decline of amphibians worldwide could suggest a corresponding deterioration of environmental conditions. However, indicator species can be used reliably to monitor environmental conditions and to inform conservation programs only if indices used as indicators, such as population size, reflect the actual measurement (e.g., abundance or density) of the species of interest (Yoccoz et al., 2001).

Two standard methods are used to accurately estimate the size of amphibian populations (Heyer et al., 1994): capture-mark-recapture methods (Seber, 1982; Bailey et al., 2004 a \& b) and depletion (removal) methods (Zippin, 1956; Bailey et al., 2004a). Although both of these methods yield reliable estimates of abundance, they are impractical to use when species have very large home ranges, low detection probability, or are cryptic or rare (Royle, 2004). Long-term monitoring programs also may not have sufficient resources to regularly (e.g., annually) repeat intensive mark-recapture or depletion studies. Finally, mark-recapture studies that rely on toe clipping or PIT tags may reduce survival and have been critiqued on ethical grounds (e.g., Clark, 1972; Heyer et al., 1994; Ott \& Scott, 1999; Green, 
64 2001; May, 2004; Dodd, 2010; Guimarães et al., 2014), and depletion studies can reduce local 65 population sizes (Hayek, 1994).

Because of these challenges, many herpetologists and conservation biologists who use amphibians, including Plethodontid salamanders, as indicator species use indices of abundance derived from simple counts of individuals under artificial cover boards, random searching of natural objects, pitfall traps, or visual encounter surveys (Heyer et al., 1994; Mathewson, 2009, 2014; Welsh \& Hodgson, 2013). Although abundance indices routinely are assumed to be proportional to absolute measures of abundance, assuming a constant capture probability (i.e., detectability), these indices may not provide accurate estimators of population size. For example, salamanders may be attracted to cover boards or pitfall traps, and random searching or visual encounter surveys may not provide reliable estimates of detection probability or occupancy, which also are rarely constant (e.g., Krebs, 1999; Pollock et al., 2002). Nonetheless, abundance indices often are easier to obtain than other estimators of population abundance, can be determined for large areas, are less intrusive, minimize harm to individuals, and are cost-effective (Royle, 2004; Pollock et al., 2002).

The trade-off between the need for reliable and cost-effective abundance indices versus laborintensive but more accurate abundance estimators has led to research that combines both methods using model-based inference (e.g., Smith, 1984; Buckland et al., 2000). Two approaches are used commonly in studies of birds and mammals. $N$-mixture models use Poisson or binomial likelihoods of abundance indices or repeated count data to obtain site-specific estimates of abundance (e.g., Royle, 2004). Alternatively, abundance indices can be calibrated to population estimates obtained from markrecapture or depletion studies (e.g., Eberhardt \& Simmons, 1987; Brown et al., 1996). However, neither $\mathrm{N}$-mixture models nor direct calibration of abundance indices have been adopted widely by herpetologists, who generally use uncalibrated abundance indices to draw inferences about population 
87 sizes and demographic rates, and then use these inferences to guide management applications

88 (Mazerolle et al., 2007). Here, we calibrate abundance indices derived from transect surveys of counts

89 of salamanders found under cover boards and natural objects with simultaneous estimates of local

90 population sizes of eastern red back salamanders (Plethodon cinereus (Greene, 1818)) obtained using

91 replicated depletion studies in a New England Forest.

This study is particularly timely because of the ongoing decline of Tsuga canadensis (L.)

Carrière, a foundation tree species in New England forests (Ellison et al., 2005). Tsuga canadensis is being killed by a non-native insect, Adelges tsugae, which is spreading rapidly throughout the eastern United States (e.g., Orwig et al., 2012). Because T. canadensis has a large range, assessment of the consequences of its decline at any particular site requires rapid, fine-scale studies of the status and trends in populations of species associated with T. canadensis. For example, the loss of the majority of T. canadensis individuals from southern and central New England forests over the next several decades is expected to lead to parallel declines in salamander populations (e.g., Ellison et al., 2005; Mathewson, 2009, 2014). Designing, validating, and implementing a long-term monitoring program for salamanders in these forests requires both accurate base-line estimates of population sizes and methods to rapidly (re)assess populations for many years to come (e.g., Bailey et al., 2004b; Mazerolle et al., 2007; Gitzen et al., 2012).

\section{Materials and Methods}

Our calibration study involved four sequential steps (Fig. 1):

1- Establishment of plots and sampling transects, and emplacement of cover boards (May 2013);

2- Simultaneous depletion sampling, surveys of natural cover objects, and surveys of cover boards (repeated twice in July 2014); 
3- Estimation of population sizes from depletion sampling;

4- Regressions of data from cover board surveys and natural object surveys on estimated population size of $P$. cinereus.

\subsection{Study species}

Plethodon cinereus is a common woodland amphibian in the family Plethodontidae. This is the largest family of salamanders, with at least 240 species (Hairston, 1987; Mathewson, 2006; Dodd, 2010). Plethodontid salamanders, including $P$. cinereus, are lungless organisms that respire through their skin (Hairston, 1987). Plethodon cinereus also has no aquatic life-history stage; rather it is completely terrestrial and spends its entire 3-7 year lifetime in forested areas, living in or under moist soils, rotting logs, leaf litter rocks, and other natural cover objects. The females lay 3-14 eggs underneath moist soils and natural objects between mid-June and mid-July; the incubation period is 6-9 weeks long (Petranka, 1998). The home range of $P$. cinereus is relatively small (13 $\mathrm{m}^{2}$ on average), and they normally move $<1 \mathrm{~m}$ /day when foraging for prey at the soil surface (Mathewson, 2006). Its limited mobility has suggested that $P$. cinereus should be an excellent indicator of changes to environmental conditions in the forested ecosystems in which they live (Welsh \& Hodgson 2013; Mathewson, 2009).

The population biology and trophic position of $P$. cinereus also is well studied. For example, Burton \& Likens (1975) reported that the density of $P$. cinereus at Hubbard Brook, New Hampshire was $\approx 0.25$ salamanders $/ \mathrm{m}^{2}$, and that their total biomass was equal to that of small mammals and twice that of breeding birds at their study site. These numbers are conservative, as only $2-32 \%$ of the local population of $P$. cinereius normally is present on or near the surface during the warm and moist or rainy nights when this species is typically sampled (Taub, 1961; Burton \& Likens, 1975). Their high 
131 abundance makes $P$. cinereus an important prey item of many birds and snakes, and this salamander 132 also is a significant predator of many soil-dwelling invertebrates including insects (Welsh \& Hodgson, 133 2013).

\section{2.2. Study site and locations of calibration plots}

135

136

137

138

139

140

141

142

143

144

145

146

147

148

149

150

151

152

This calibration study was done at the Simes Tract (Ellison et al., 2014) within the Harvard Forest Long-term Ecological Research (LTER) site in Petersham, Massachusetts, USA (42.47$42.48^{\circ} \mathrm{N}, 72.22^{\circ}-72.21^{\circ} \mathrm{W}$; elevation $215-300 \mathrm{~m}$ a.s.1.). All measurements were taken within four separate forest stands. Two of these stands were dominated by eastern hemlock (Tsuga canadensis) and the other two were composed of mixed deciduous species, including oaks (Quercus spp.) and maples (Acer spp.) species (Fig. 3). The two hemlock sites were in a moist valley, whereas the two deciduous locations were on a drier ridge $\approx 500 \mathrm{~m}$ from the valley. Individual stands within a forest type were separated by $>100 \mathrm{~m}$, so all four sites can be considered independent replicates.

Transects for depletion sampling, natural object surveys, and cover boards were established in May 2013. Within each stand, we laid out three parallel $30 \times 1$-m strip transects, separated from one another by $10 \mathrm{~m}$ (Fig. 2). Depletion sampling and natural object surveys were done along all three transects. Along each of two of these transects (the outer ones) in each stand, we placed five cover boards $(1 \times 0.25 \times 0.02 \mathrm{~m}$ rough-sawn $T$. canadensis planks $)$ spaced $5 \mathrm{~m}$ from one another. To ensure that the lower surface of each cover board was in contact with the soil surface, leaf litter directly under the cover board was removed before the cover board was laid down. To minimize effects of the disturbance of establishing the sampling locations on detection of $P$. cinereus, and to allow for appropriate weathering (Mathewson, 2009; Hesed, 2012), all sampling was done in July 2014, 14 months after the sites had been selected, transects laid out, and cover boards placed in the field. 
153 Following each sampling day, all transects, including natural objects on the forest floor, were left in

154 similar conditions to those seen at the start of the day.

\section{2.3. Salamander sampling}

Depletion sampling of $P$. cinereus, surveys of these salamanders under natural cover objects,

157 and counts of individual salamanders under cover boards in all four plots occurred during two four-day

158 sessions in July 2014. The first session ran from 14-17 July, and the second from 27-30 July. All

159 sampling was done on the morning of each day between 0700 and 1100 hours.

\section{$160 \quad$ 2.3.1. Depletion sampling}

Our depletion sampling procedure followed that developed by Hairston (1986), Petranka \&

162 Murray (2001), and Bailey et al. (2004a). Every morning during each of the two four-day sampling

163 sessions, we intensively searched for salamanders for $\approx 4$ hours under dead wood, rocks, and leaf litter

164 in each transect in each plot. All salamanders encountered in each transect were removed and placed

165 into $0.7 \times 0.3 \times 0.15$-m plastic baskets buried $5 \mathrm{~m}$ outside of the sampling zones. The bottom $10 \mathrm{~cm}$ of

166 each basket was filled with dirt and leaf litter to provide moist habitat and food; small holes were

167 drilled in the bottom of each basket to allow rain water to drain; and baskets were covered with mesh

168 netting to provide shade and protection from predators (Corn, 1994). All salamanders collected from

169 the transects were kept in these baskets for the entire sampling session (up to 72 hours), and were

170 released thereafter back into the study plots from which they had been collected.

\section{$171 \quad$ 2.3.2. Cover-board sampling}


We lifted up each cover board, counted the number of $P$. cinereus that we saw under it

173 (Mathewson, 2009; Hesed, 2012), removed the salamanders from under the cover boards, and placed

174 them in the holding baskets.

\section{2.4. Abundance estimations and calculation of abundance indices}

176

The three abundance estimates were calculated for each sampling session separately. From the data collected from the depletion surveys, we estimated capture probability and population size of $P$. cinereus in each plot using Zippin's regression method (Zippin, 1956, 1958) as implemented in the Removal Sampling software, version 2.2.2.22 (Seaby \& Henderson, 2007). In this method, the total number of individuals captured and removed from the sampling area (i.e., each transect) each day was plotted as a function of the cumulative number of captures on previous days in the same transect. The estimated population size for each transect is defined as the point where the regression line intercepts the $x$-axis, and the capture probability as the slope of the regression line (Zippin, 1956, 1958; Seaby \& Henderson, 2007). Estimates of population size per $\mathrm{m}^{2}$ or per ha were obtained by division (we sampled $30 \mathrm{~m}^{2}$ per transect $)$ or multiplication $\left(1 \mathrm{ha}=10,000 \mathrm{~m}^{2}\right)$, respectively.

A transect-level cover-board index (salamanders $/ \mathrm{m}^{2}$ ) was estimated as the average of the number of salamanders detected during the first day of each sampling session under all five cover boards in the transect, multiplied by 4 (the area of a single cover board $=0.25 \mathrm{~m}^{2}$ ). Similarly, a transect-level natural object survey index (salamanders $/ \mathrm{m}^{2}$; excluding the cover boards) was estimated as the total number of salamanders captured during the first day of sampling in each transect divided by 30 (the total area of strip transects searched for salamanders was $30 \times 1 \mathrm{~m}^{2}=30 \mathrm{~m}^{2}$ ). In both cases, we calculated population indices for each sampling session only from the first day of captures to avoid 
193 effects of habitat disturbance (from searching) and ongoing removal sampling on the subsequent three 194 days of detection and capture of salamanders.

\section{2.5. Calibration of indices}

196

197

198

199

We calibrated the two density indices (from cover boards and natural objects) by regressing them against the estimates of population size derived from depletion sampling (Eberhardt, 1982).

\section{Results}

Between both sampling sessions and summed over all three sampling methods, we captured or detected a total of 101 P. cinereus individuals: 53 individuals were captured in the first sampling session and 48 in the second. There was no significant difference between the number of salamanders captured in the hemlock plots (59) and the hardwood plots (42) (Wilcoxon rank sum test: $W=24, P=$ 0.18). As is typically found in depletion studies, the total number of captures/day declined continuously in both forest types, and cumulative captures generally leveled off by the fourth day of sampling during each session (Fig. 4).

The average population density of $P$. cinereus estimated from the depletion surveys ranged from 0.13 (hardwood) to 0.18 (hemlock) salamanders $/ \mathrm{m}^{2}$ (1330 to 1816 salamanders/ha), with an overall average of 0.15 salamanders $/ \mathrm{m}^{2}(1550 / \mathrm{ha})$ (Table 1$)$. The average capture probability in the hemlock stands was 0.51 , about $15 \%$ lower than that in the hardwood stands (0.64). In contrast, the average relative density suggested by cover-board observations was 1.7 individuals $/ \mathrm{m}^{2}$ in the hemlock stands and 0.7 salamanders $/ \mathrm{m}^{2}$ in the hardwood stands, with an overall average of 1.2 salamanders $/ \mathrm{m}^{2}$. Last, the estimated density of $P$. cinereus from searches of natural objects within each $30 \times 1-\mathrm{m}$ transects was 0.1 and 0.06 salamanders $/ \mathrm{m}^{2}$ in the hemlock and hardwood stands, respectively with an 
214 overall average of 0.08 salamanders $/ \mathrm{m}^{2}$. Overall, there were no significant differences between forest 215 stand types in any of these estimates (Table 1).

216 Because we found no differences between forest-stand types in salamander density or 217 abundance indices, we pooled the data from the two forest-stand types when we calibrated the two 218 indices using the estimated population density (Fig. 5). The estimated true density of P. cinereus was 219 predicted well by the natural-objects survey $\left(r^{2}=0.65, P=0.001\right.$; Fig. 5) but the cover-board index 220 was weakly and not significantly associated with the estimated true population density $\left(r^{2}=0.30, P=\right.$ 221 0.158). The density index from the natural object survey underestimated the estimated population density of $P$. cinereus by $50 \%$, whereas the cover-board index overestimated the estimated population 223 density of $P$. cinereus by a factor of eight (Fig. 5).

\section{Discussion}

Estimation of the abundance of organisms is at the core of population biology and conservation practice (Krebs, 1999). However, in spite of the importance of accurate estimates of population size, many ecologists and environmental scientists use abundance indices that rarely are calibrated with actual abundance data. We have shown here that, with only modest effort, at least one abundance index for $P$. cinereus can be calibrated reasonably well, allowing for stronger inferences regarding 231 salamander population size.

Our results represent the first time, to our knowledge, that an abundance index of salamander population size has been calibrated to actual density estimates in northeastern North America. Our results suggest that rapid surveys of natural cover objects in two forest types (hemlock or mixed deciduous stands) correspond reasonably well with estimates of population size obtained from more careful, labor-intensive depletion samples. Our results also were similar to relative abundance of $P$. 
237 cinereus found during cover-board surveys a decade ago at Harvard Forest (Mathewson 2009).

238 However, our estimates of abundance from depletion sampling (1816 salamanders/ha) were $20 \%$ lower 239 than those found in hardwood forests at Hubbard Brook, New Hampshire (2243 salamanders/ha;

240 Burton \& Likens, 1975). Both of these density estimates are likely to be quite conservative, as Taub 241 (1961) suggested that only $2-32 \%$ of a local population of $P$. cinereus is available for sampling on the 242 soil surface or within the topsoil during a given period of time. Although the abundance index obtained by natural object surveys was well calibrated with the 244 population size estimator from depletion sampling, the cover-board index was not well calibrated. The overestimation of population density suggested by cover board surveys were not surprising, as cover boards provide additional protected habitat at the soil surface that should be attractive to $P$. cinereus

247 (Hesed, 2012). The spatial heterogeneity in P. cinereus individuals and their relatively low mobility also may have contributed to the large variability in the cover-board index ( $\mathrm{CV}=77 \%$; Table 1$)$.

249 Overall, we conclude that population indices of $P$. cinereus from natural objects surveys are more reliable than indices from cover-board surveys within our study area. requires that all the different sampling methods be done simultaneously over a large area, a process that is labor (and hence, cost) intensive. If salamander sampling is part of a long-term monitoring program, we recommend that calibration should occur regularly. If consistent results are achieved with a series of annual calibrations, it is possible that, longer times between re-calibrations, perhaps every $4-5$ year could be considered to capture the effects of, for example, changing environments. We also note that we used linear relationships to calibrate population indices with density estimates but the relationship between density and abundance indices may be non-linear (Pollock et al., 2002). 
261 repeating more intensive, invasive, or destructive methods (e.g., capture-mark-recapture surveys, pitfall 262 traps, or depletion surveys). Although our data and calibrations are applicable only to the forest we 263 studied in central Massachusetts and its particular weather conditions, the method for calibrating 264 abundance indices is generalizable to any site. We recommend that any abundance index be routinely 265 recalibrated just as one would do with an electronic sensor. Such calibrated abundance indices could 266 lead to cost-effective indicators that are straightforward to implement in large-scale conservation 267 programs and broader ecological research (e.g., Noss, 1990; Gitzen et al., 2012, or the U.S. Geological 268 Survey's Amphibian Research and Monitoring Initiative: http://armi.usgs.gov).

\section{Acknowledgements}

We thank Allyson Degrassi (University of Vermont) and the six undergraduate researchers who participated in this project during the 2014 Harvard Forest Summer Research Program in Ecology -

272 Alison Ochs, Claudia Villar-Lehman, Simone Johnson, Ariel Reis, Jessica Robinson, and Joel van de 273 Sande -for helping us with intensive field work and data collection. Two anonymous reviewers and the 274 academic editor at PeerJ provided useful comments on an earlier version of the manuscript. All field 275 sampling protocols were approved by Harvard University's Institutional Animal Care and Use

276 Committee, File 13-02-144 - June 02, 2014. This work is a publication of the Harvard Forest LTER and REU Sites (supported by NSF grants 0620443, 1003938, and 1237491). The senior author was supported by a scholarship from the Islamic Development Bank (IDB). 
283 Bailey LL, Simons TR, Pollock KH. 2004a. Comparing population size estimators for plethodontid 284 salamanders. Journal of Herpetology 38:370-380.

285 Bailey LL, Simons TR, Pollock KH. 2004b. Estimating site occupancy and species detection 286 probability parameters for terrestrial salamanders. Ecological Applications 14:692-702.

287 Becker CG, Fonseca CR, Haddad CFB, Batista RF, Prado PI. 2007. Habitat split and the global decline $288 \quad$ of amphibians. Science $318: 1775-1777$

289 Brown KP, Moller H, Innes J, Alterio N. 1996. Calibration of tunnel tracking rates to estimate relative 290 abundance of ship Rates (Rattus rattus) and Mice (Mus musculus) in a New Zealand forest. New Zealand Journal of Ecology 20: 271-275. future directions. Biometrics 56: 1-12.

Burton TM, Likens GE. 1975. Salamander populations and biomass in the Hubbard Brook

Buckland ST, Goudie IBJ, Borchers DL.2000. Wildlife population assessment: past developments and Experimental Forest, New Hampshire. Copeia 1975:541-546.

Burton TM. 1976. An analysis of the feeding ecology of salamanders (Amphibia, Urodela) of the Hubbard Brook Experimental Forest, New Hampshire. Journal of Herpetology 10:187 - 204.

Clark RD. 1972. The effect of toe clipping on survival in Fowler's toad (Bufo woodhousei fowleri). Copeia 1972: 182-185.

Corn PS. 1994. Standard techniques for inventory and monitoring: straight-line drift fences and pitfall traps. Pages 109-117 in: Heyer WR, Donnelley MA, McDiarmid RW, Hayek LC, Foster MS, editors. Measuring and monitoring biological diversity. Standard methods for amphibians. Smithsonian Institution Press, Washington, D.C., USA.

Dodd CK Jr.. 2010. Amphibian ecology and conservation: a handbook of techniques. Oxford University Press, New York. 
306 Eberhardt LL, Simmons MA. 1987. Calibrating population indices by double sampling. The Journal of Wildlife Management 51: 665-675.

308 Eberhardt LL.1982. Calibrating an index by using removal data. The Journal of Wildlife Management 46: 734-740.

Ellison AM, Bank MS, Clinton BD, Colburn EA, Elliott K, Ford CR, Foster DR, Kloeppel BD, Knoepp JD, Lovett GM, Mohan J, Orwig DA, Rodenhouse NL, Sobczak WV, Stinson KA, Stone JK., Swan CM, Thompson J, Von Holle B, Webster JR. 2005. Loss of foundation species: consequences for the structure and dynamics of forested ecosystems. Frontiers in Ecology and Environment; 3:479-486

Ellison AM, Lavine M, Kerson PB, Barker Plotkin AA, Orwig DA. 2014. Building a foundation: landuse history and dendrochronology reveal temporal dynamics of a Tsuga canadensis (Pinaceae) forest. Rhodora 116:377-427.

Gitzen RA, Millspaugh JJ, Cooper AB, Licht DS. 2012. Design and analysis of long-term ecological monitoring studies. Cambridge University Press, New York, USA.

Green DE. 2001. Toe-clipping of frogs and toads. Standard Operating Procedure ARMI SOP 110, National Wildlife Health Center, US Geological Survey. Available online: http://www.nwhc.usgs.gov/publications/amphibian_research_procedures/toe_clipping.jsp.

Guimarães M, Corrêa DC, Filho SS, Oliveria TAL, Doherty Jr PF, Sawaya RJ. 2014. One step forward: contrasting the effects of toe clipping and PIT tagging on frog survival and recapture probability. Ecology and Evolution 4:1480-1490.

Hairston NG. 1987. Community ecology and salamanders guilds. Cambridge University Press, New York.

Hairston NG. 1986. Species packing in Desmognathus salamanders: experimental demonstration of predation and competition. American Naturalist 127:266-291. 
330 Hayek LC. 1994. Removal methods. Pages 201-205 in: Heyer WR, Donnelley MA, McDiarmid RW, Hayek LC, Foster MS, editors. Measuring and monitoring biological diversity. Standard methods for amphibians. Smithsonian Institution Press, Washington, D.C., USA.

Hesed KM. 2012. Uncovering salamander ecology: a review of cover board design. Journal of

Krebs JC. 1999. Ecological methodology, $2^{\text {nd }}$ edition. A. Wesley Longman, New York, USA.

Lanoo M. 2005. Amphibian declines: the conservation status of United States species. The University of California Press, Berkeley, California, USA.

Mathewson B. 2006. Differences in eastern red backed salamanders (Plethodon cinereus) populations in hemlock-dominated and mixed deciduous forests in north-central Massachusetts. M.F.Sc. Thesis,Harvard University, Cambridge, Massachusetts, USA.

Mathewson B. 2009. The relative abundance of eastern red-backed salamanders in eastern hemlockdominated and mixed deciduous forests at Harvard Forest. Northeastern Naturalist 16:1-12.

Mathewson B. 2014. The relative abundance of the juvenile phase of the eastern red-spotted newt at Harvard Forest prior to the arrival of the hemlock woolly adelgid. Southeastern Naturalist 13(Special Issue 6):117-129. 
354 May RM. 2004. Ethics and amphibians. Nature 431:403.

355 Mazerolle MJ, Bailey LL, Kendall WL, Royle JA, Converse SJ, Nichols JD. 2007. Making great leaps 356 forward: accounting for detectability in herpetological field studies. Journal of Herpetology; 41:672-689.

Noss RF. 1990. Indicators for monitoring biodiversity: a hierarchical approach. Conservation Biology

Orwig DA, Thompson JR, Povak NA, Manner M, Niebyl D, Foster DR. 2012. A foundation tree at the precipice: Tsuga canadensis health after the arrival of Adelges tsugae in central New England. Ecosphere 3:art10.

Ott JA, Scott DE. 1999. Effects of toe-clipping and PIT-tagging on growth and survival in metamorphic Ambystoma opacum. Journal of Herpetology 33:344-348.

Petranka JW, Murray SS. 2001. Effectiveness of removal sampling for determining salamander density and biomass: a case study in an Appalachian streamside community. Journal of Herpetology $35: 36-44$

Petranka JW. 1998. Salamanders of the United States and Canada. Smithsonian Institution Press, Washington, DC, USA.

Pollock KH, Nichols JD, Simons TR, Farnsworth GL, Bailey LL, Sauer JR. 2002. Large scale wildlife monitoring studies: statistical methods for design and analysis. Environmetrics 13:105-119.

Royle JA. 2004. $\mathrm{N}$-mixture models for estimating population size from spatially replicated counts. Biometrics 60:108-115

Seaby RMH, Henderson PA. 2007. Removal Sampling 2. Pisces Conservation Ltd., Lymington, England.

Seber GAF. 1982. The estimation of animal abundance and related parameters, 2nd edition. Charles. W. Griffin Press. London, England. 
378 Smith TMF. 1984. Sample surveys, present position and potential developments: Some personal views (with discussion). Journal of the Royal Statistical Society, Series A 147:208-221.

380 Taub FB. 1961. The distribution of the red-backed salamander, Plethodon c. cinereus, within the soil. Ecology 42:681-698.

382 Welsh HH, Hodgson GR. 2013. Woodland salamanders as metrics of forest ecosystem recovery: a case 383 study from California's redwoods. Ecosphere 4:art59.

384 Yoccoz NG, Nichols JD, Boulinier T. 2001. Monitoring of biological diversity in space and time. 385 Trends in Ecology \& Evolution 16:446-453.

386 Zippin C. 1956. An evaluation of the removal method of estimating animal populations. Biometrics 387 12:163-189.

388 Zippin C. 1958.The removal method of population estimation. The Journal of Wildlife Management 389 22:82-90. 
392 Table 1. Mean estimates (standard error of the mean) of $P$. cinereus population size (salamanders $/ \mathrm{m}^{2}$ )

393 based on depletion sampling, surveys of cover boards, and surveys under natural objects at the Simes

394 Tract, Harvard Forest. Tests for significant differences in each estimate were done using the Wilcoxon 395 rank-sum test.

\begin{tabular}{|c|c|c|c|c|}
\hline \multirow[b]{2}{*}{ Salamanders $/ \mathrm{m}^{2}$} & \multicolumn{2}{|l|}{ Forest type } & \multirow[b]{2}{*}{ Wilcoxon's $W$} & \multirow[b]{2}{*}{$P$ value } \\
\hline & Hemlock & Hardwood & & \\
\hline Depletion sampling & $0.18(0.03)$ & $0.13(0.02)$ & 6.5 & 0.461 \\
\hline Cover-board index & $1.7(0.4)$ & $0.7(0.17)$ & 0 & 0.125 \\
\hline Natural-object survey index & $0.1(0.02)$ & $0.06(0.01)$ & 7 & 0.562 \\
\hline
\end{tabular}

396

397

398

399

400

401

402

403

404

405

406

407 
Step 1: Identifying population size estimator \& abundance index of interest

e.g. Depletion method

e.g. Artificial or Natural Cover Objects Surveys

$\downarrow$

Step 2: Study design and data collection

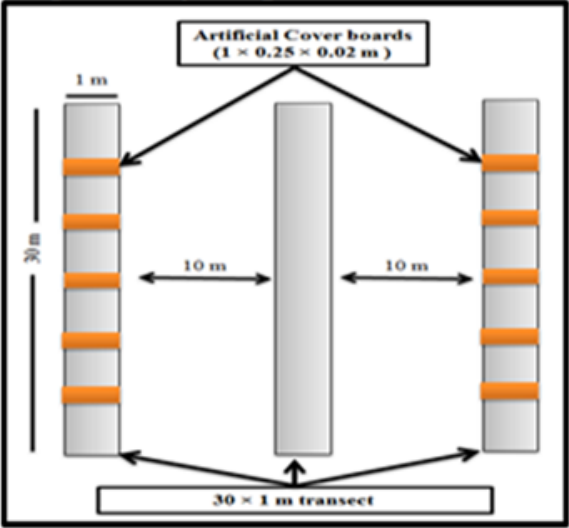

$\downarrow$

Step 3: Computing pop.size \& abundance index estimates salamanders/min $\mathbf{m}^{2}$ salamanders/ha salamanders/coverboard salamanders/mi2

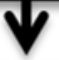

Step 4: Establishing a relationship between abundance index \& pop. size estimates

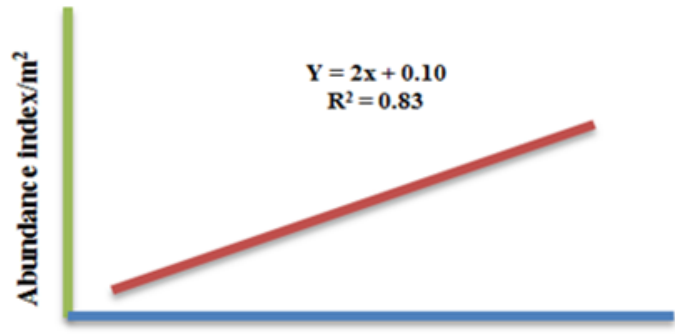

Population Estimator $/ \mathbf{m}^{2}$

409 Figure 1. Framework for calibrating salamander abundance indices with population size estimators. 


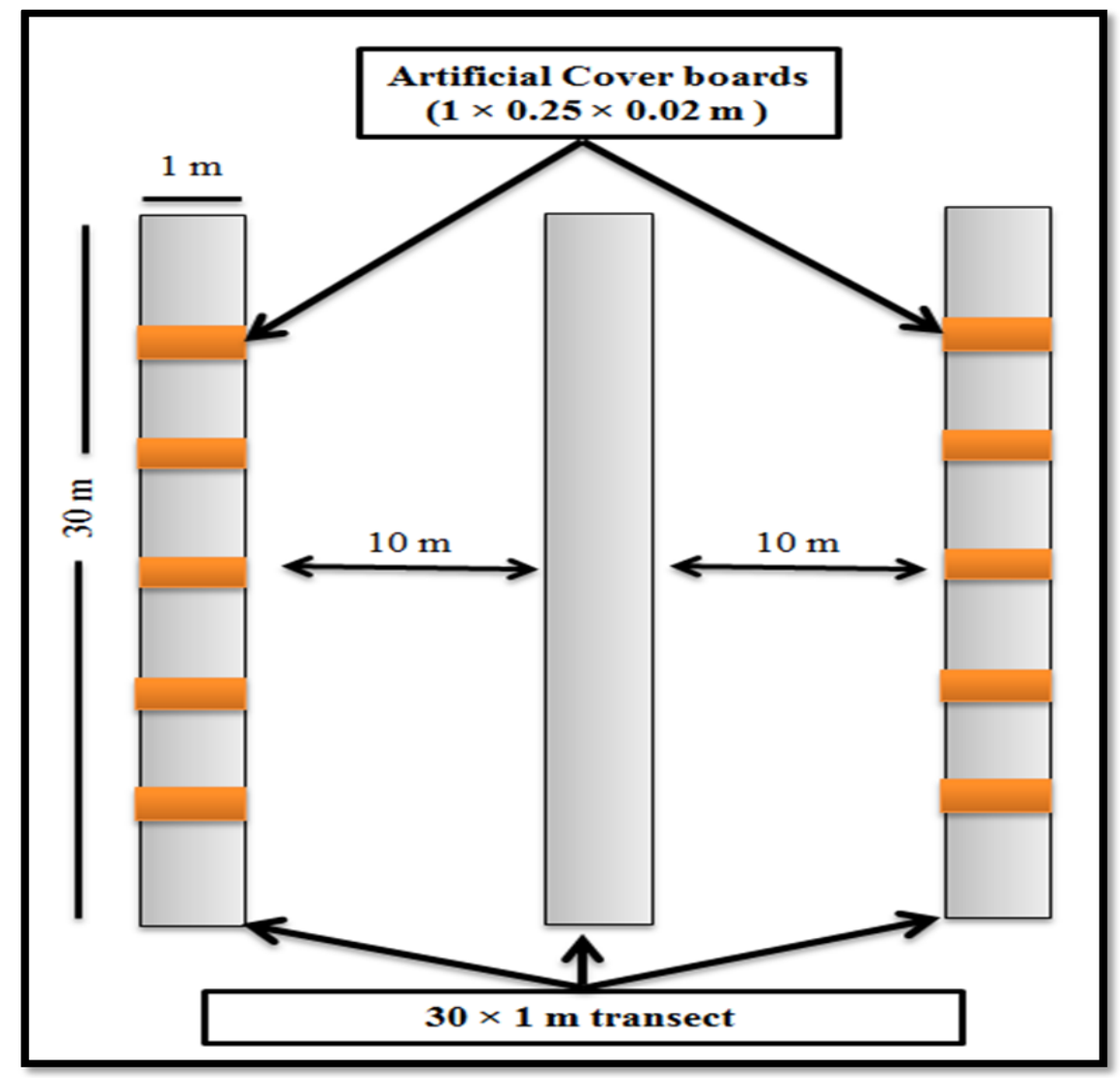

419 Figure 2. Sampling design showing the layout of the sampling transects and arrangement of the cover

420 boards at the Simes Tract of the Harvard Forest, Petersham, Massachusetts. 


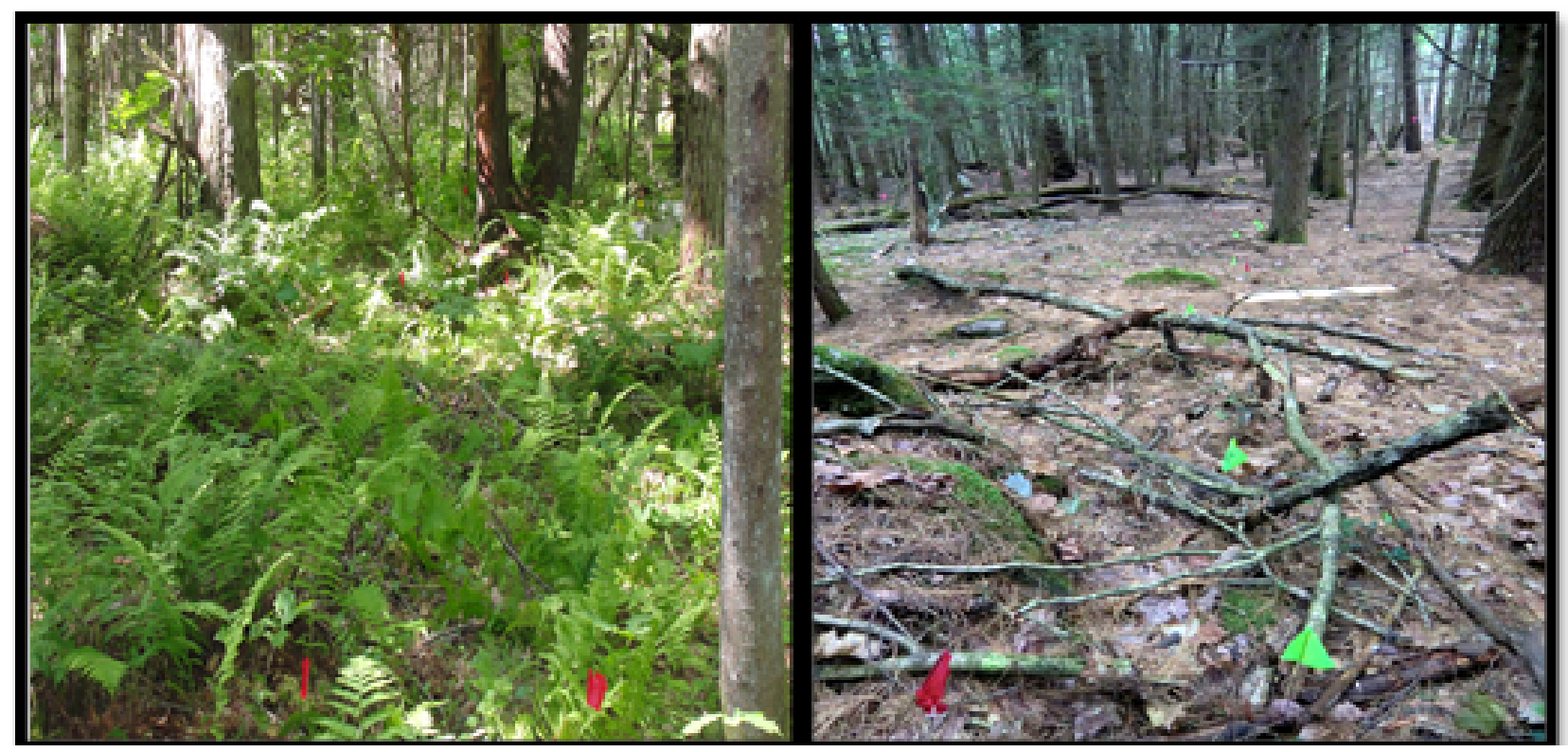

427 Figure 3. Photographs (June 2014) of the understory of one of the deciduous forest stands (left) and

428 one of the hemlock stands (right) in which calibration plots were established. 


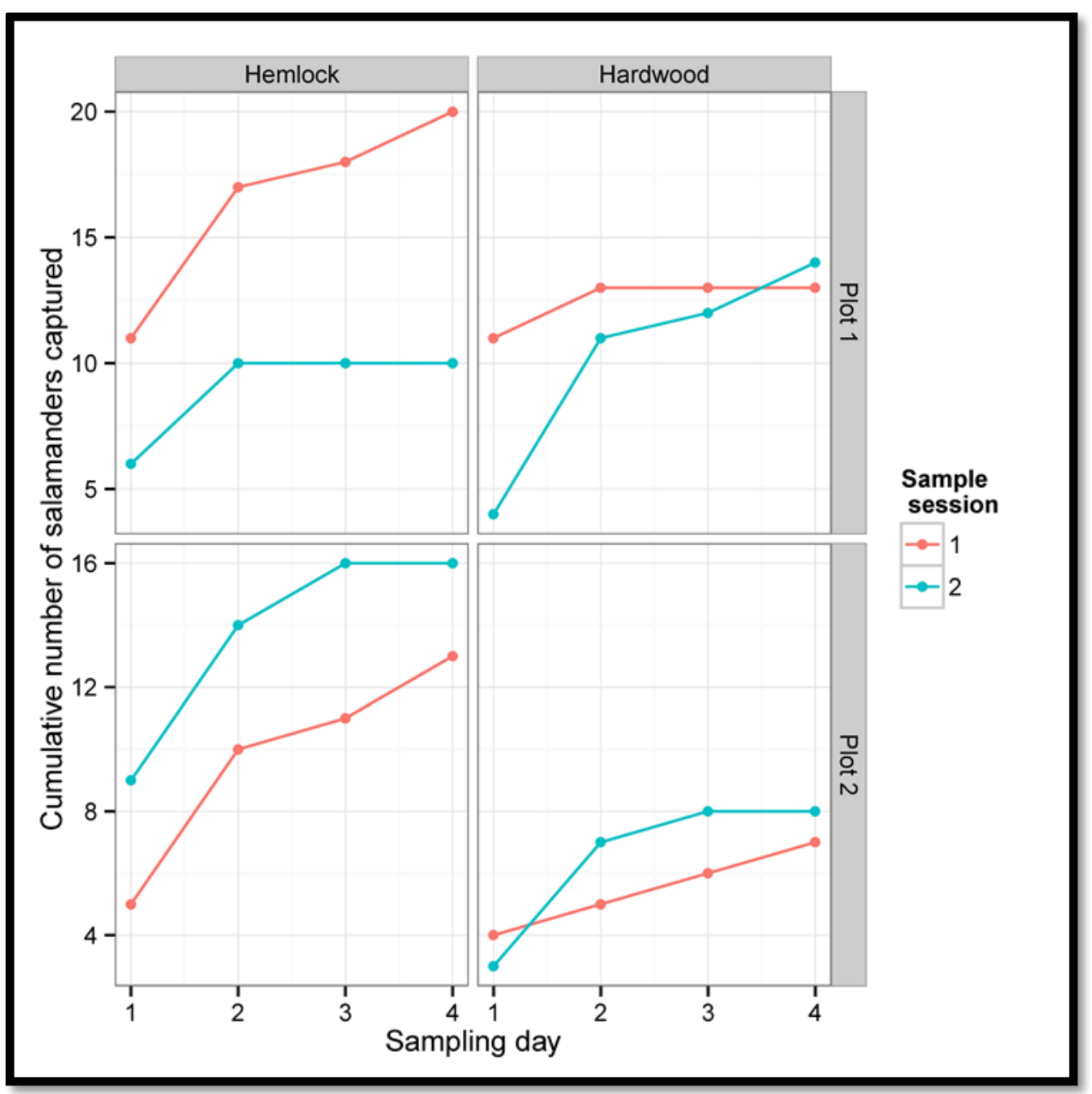

432 Figure 4. Cumulative numbers of salamanders captured during each depletion sampling session. Each 433 panel illustrates the cumulative number of salamanders captured in a single plot in either hemlock or

434 the hardwood stands. The data for each 4-day sampling session in each plot $\times$ forest type combination 435 are shown in different colors. 


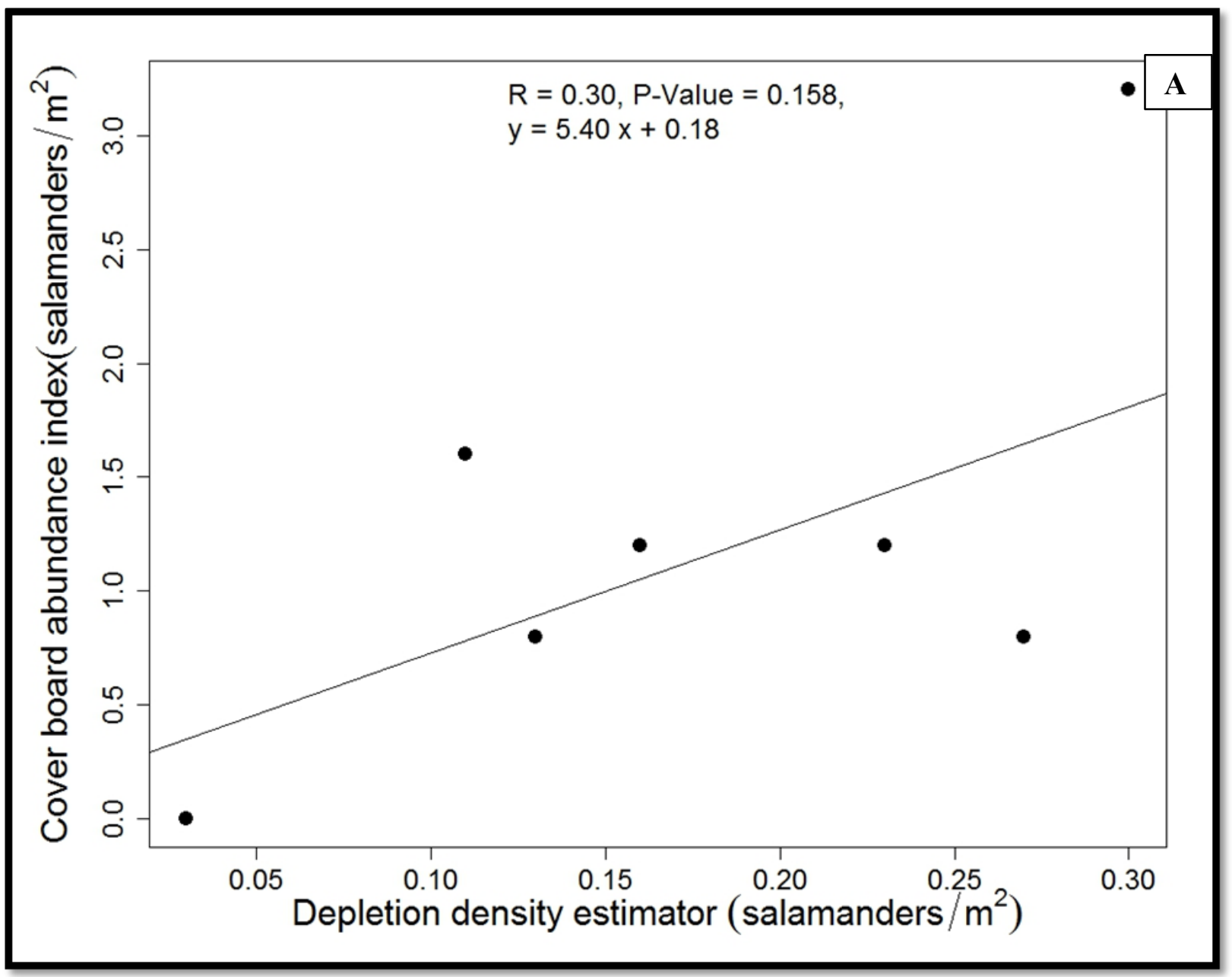




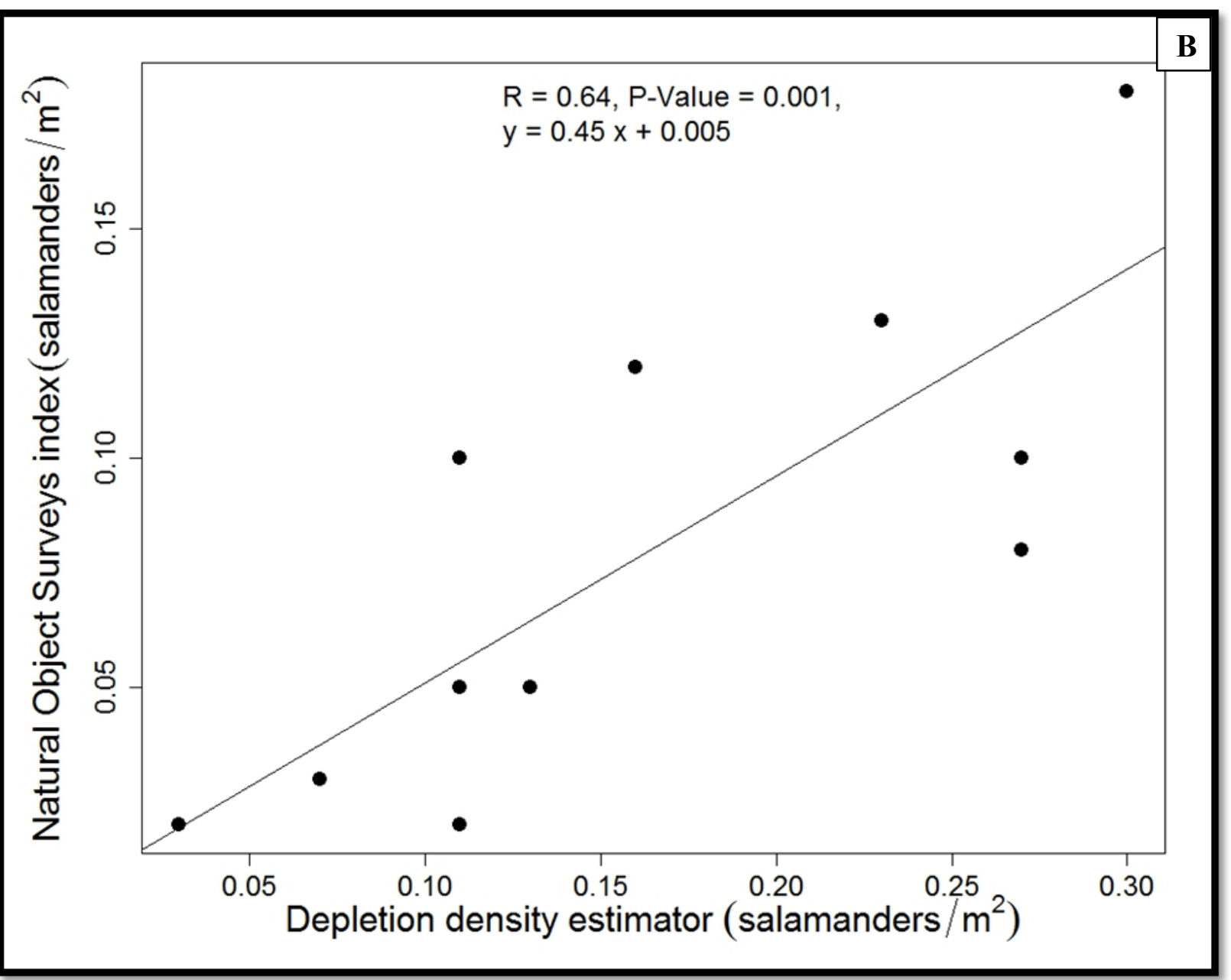

448 Figure 5. Regressions of population estimates (salamanders $/ \mathrm{m}^{2}$ ) based on depletion sampling and

449 abundance indices (salamanders $/ \mathrm{m}^{2}$ ) from (A) cover board surveys and (B) natural-object surveys of $P$.

450 cinereus at the Simes Tract. 
Table $\mathbf{1}_{\text {(on next page) }}$

Mean estimates (standard error of the mean) of $P$. cinereus population size and abundance indices.

Table 1. Mean estimates (standard error of the mean) of $P$. cinereus population size (salamanders $/ \mathrm{m}^{2}$ ) based on depletion sampling, surveys of cover boards, and surveys under natural objects at the Simes Tract, Harvard Forest. Tests for significant differences in each estimate were done using the Wilcoxon rank-sum test. 


\begin{tabular}{lllll}
\hline & \multicolumn{2}{l}{ Forest type } & & \\
\cline { 2 - 3 } Salamanders $/ \mathrm{m}^{2}$ & Hemlock & Hardwood & Wilcoxon's $W$ & $P$ value \\
\hline Depletion sampling & $0.18(0.03)$ & $0.13(0.02)$ & 6.5 & 0.461 \\
Cover-board index & $1.7(0.4)$ & $0.7(0.17)$ & 0 & 0.125 \\
Natural-object survey index & $0.1(0.02)$ & $0.06(0.01)$ & 7 & 0.562 \\
\hline
\end{tabular}

5

6

7 
Figure 1 (on next page)

calibrating salamander abundance indices.

Figure 1. Framework for calibrating salamander abundance indices with population size estimators. 
Step 1: Identifying population size estimator $\&$ abundance index of interest e.g. Depletion method e.g. Artificial or Natural Cover Objects Surveys

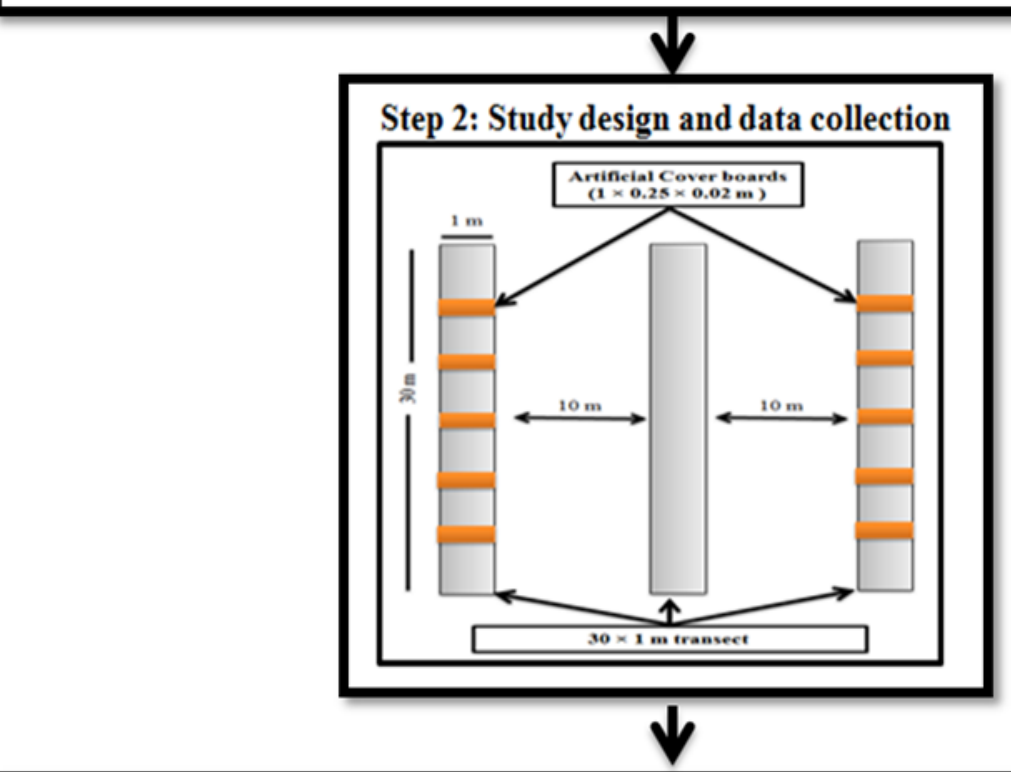

Step 3: Computing pop. size \& abundance index estimates salamanders $/ \mathbf{m}^{2}$ salamanders/coverboard salamanders/ha salamanders/ $\mathbf{m}^{2}$

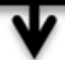

Step 4: Establishing a relationship between abundance index \& pop. size estimates

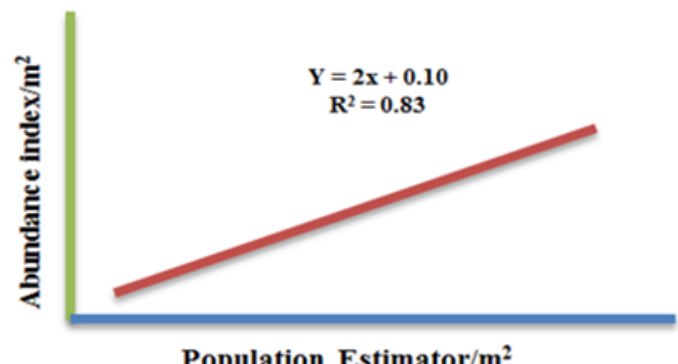

Population Estimator/m² 
Figure 2 (on next page)

Sampling design.

Figure 2. Sampling design showing the layout of the sampling transects and arrangement of the cover boards at the Simes Tract of the Harvard Forest, Petersham, Massachusetts. 


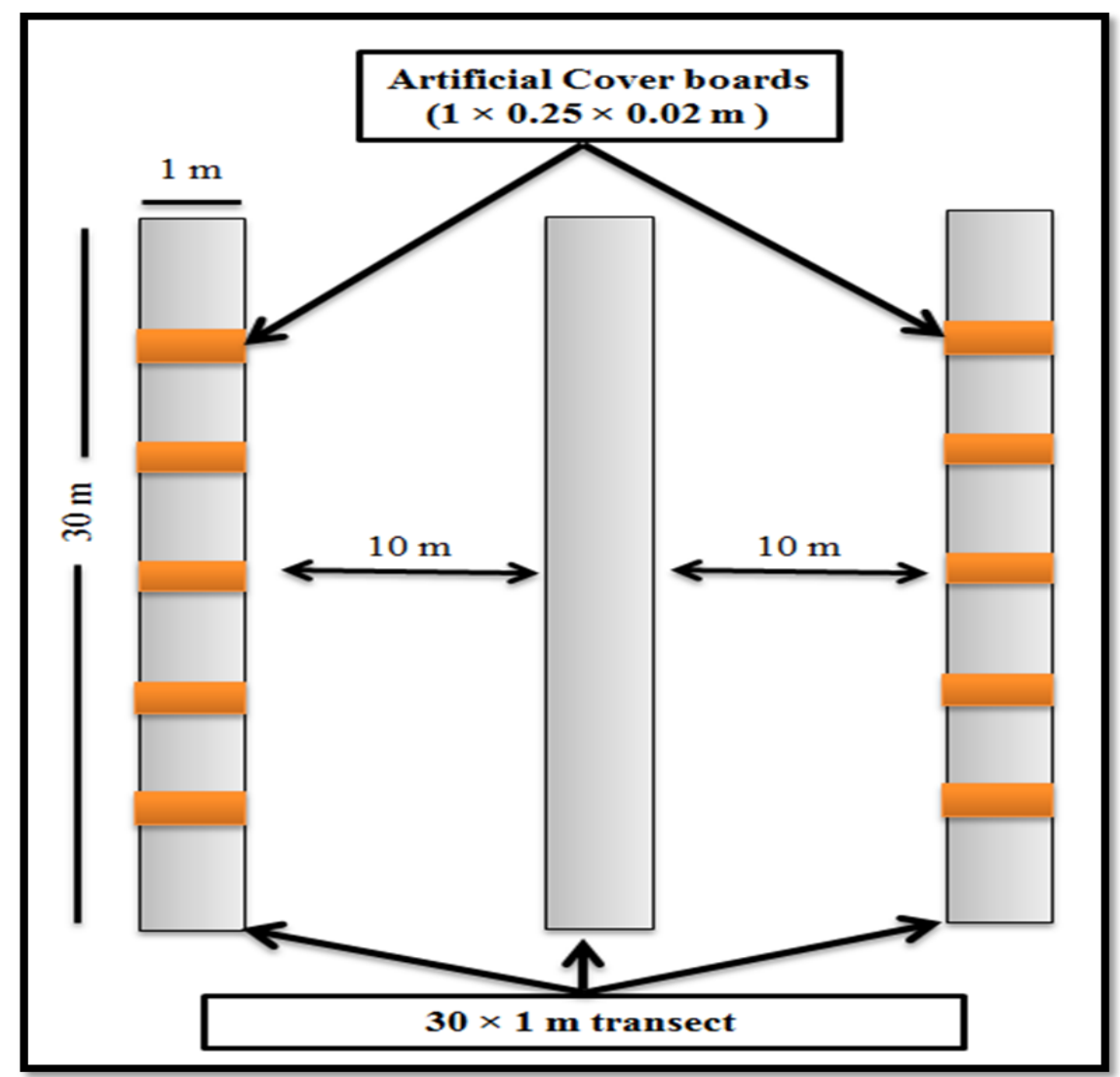


Figure 3 (on next page)

Photographs of the study area. 
PeerJ Reviewing Manuscript

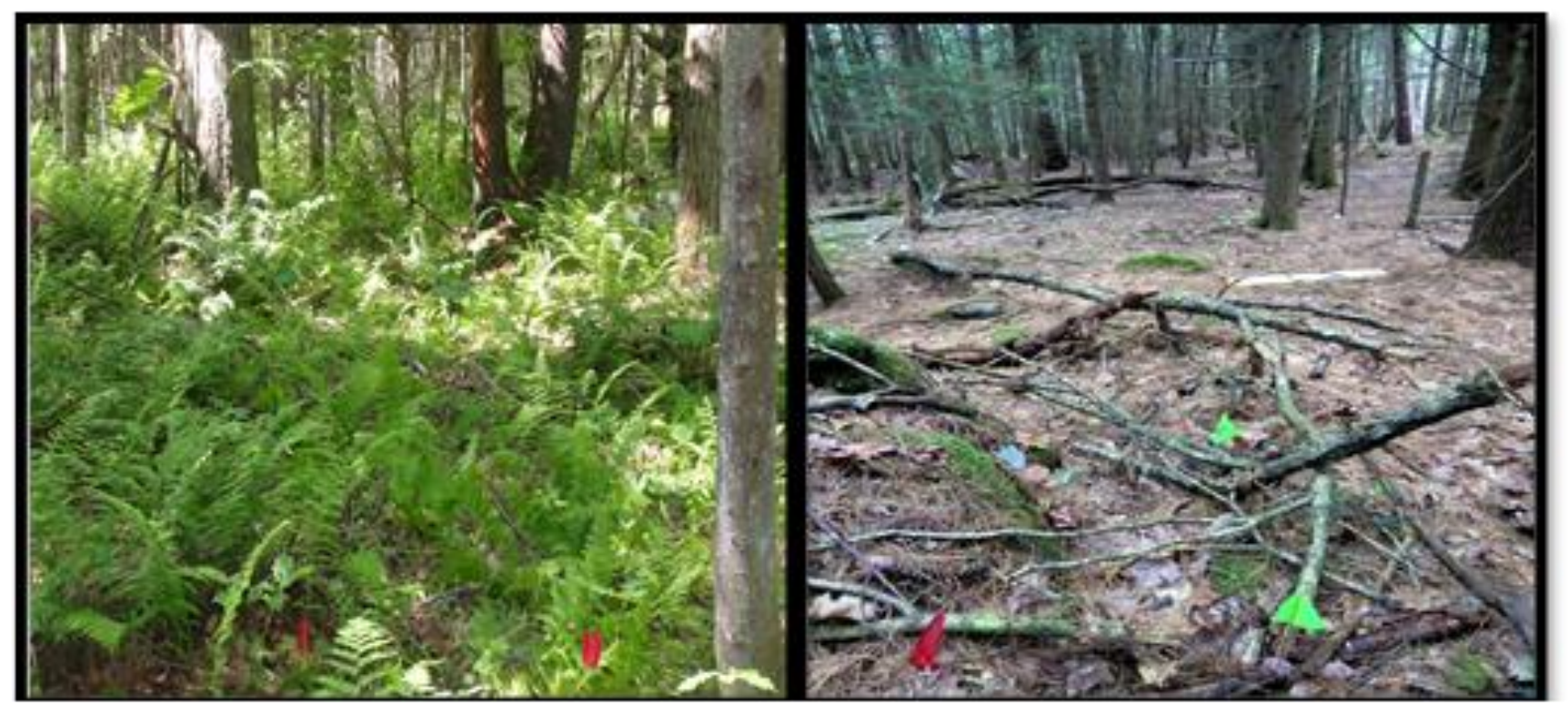




\section{Figure 4 (on next page)}

Cumulative numbers of salamanders captured during each depletion sampling session.

Figure 4. Cumulative numbers of salamanders captured during each depletion sampling session. Each panel illustrates the cumulative number of salamanders captured in a single plot in either hemlock or the hardwood stands. The data for each 4-day sampling session in each plot $x$ forest type combination are shown in different colors. 


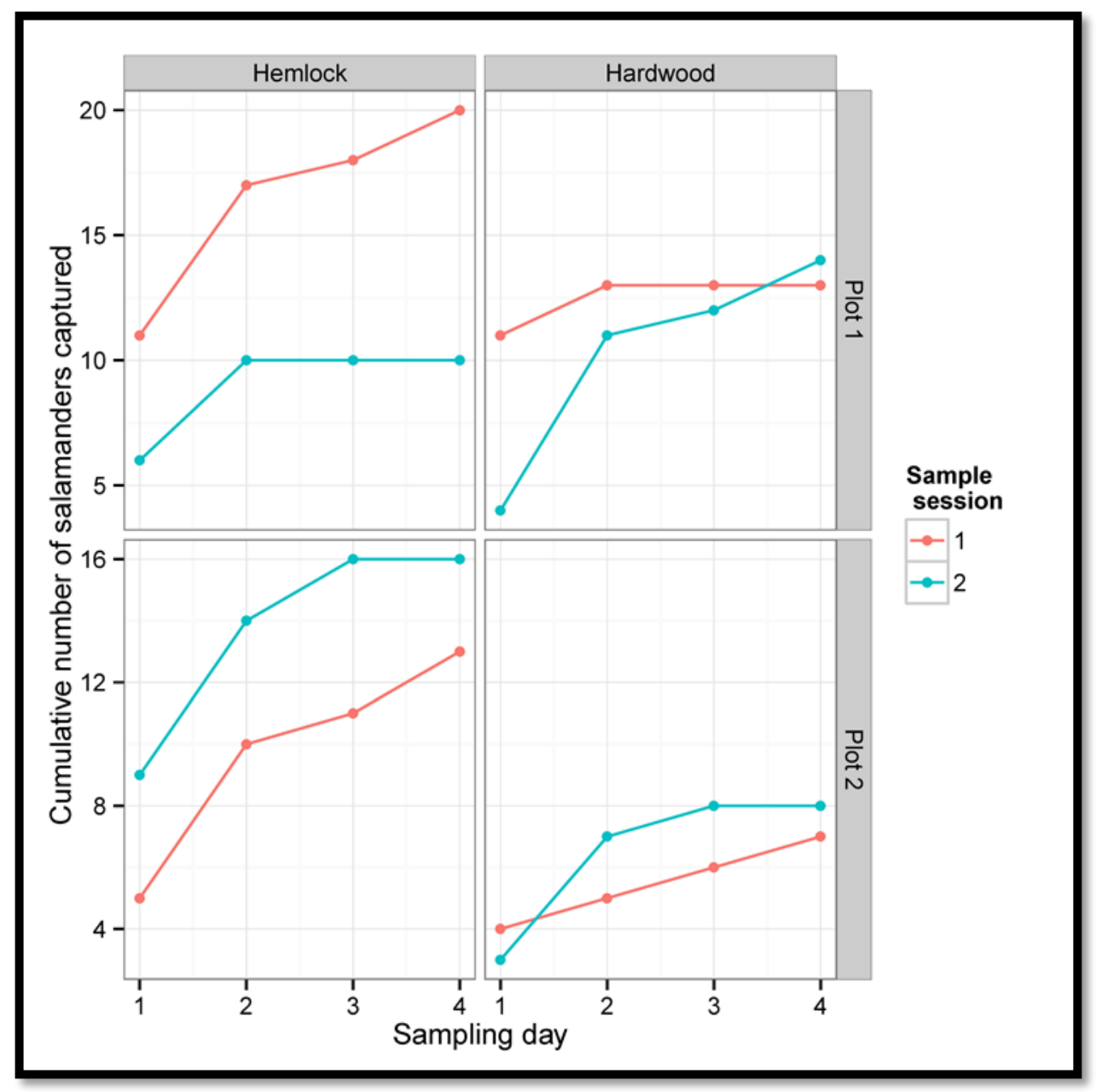


Figure 5 (on next page)

Regressions of population estimates (salamanders $/ \mathrm{m}^{2}$ ). 


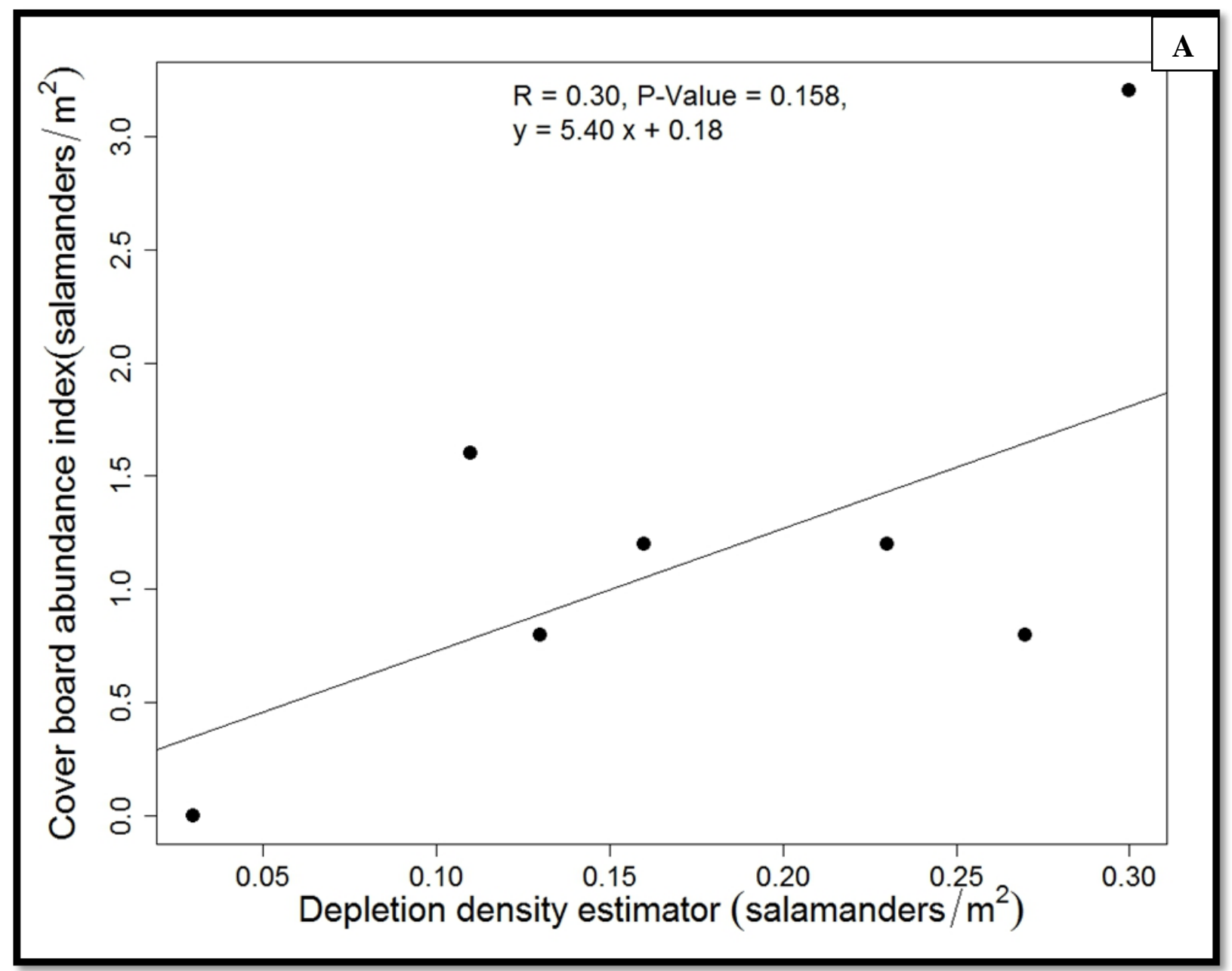




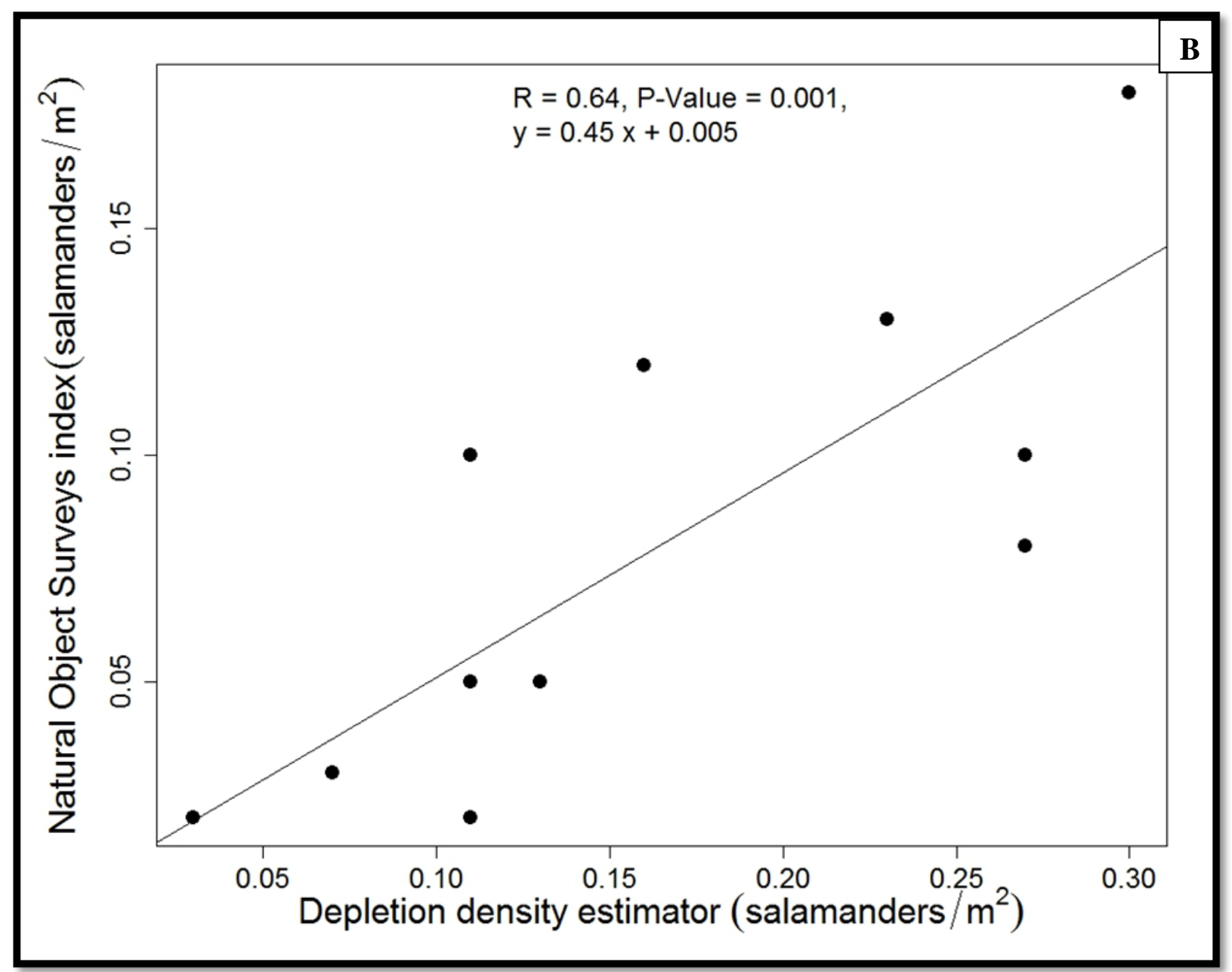

